\title{
Expression, purification, crystallization, and preliminary X-ray crystallographic studies of the human adiponectin receptors, AdipoR1 and AdipoR2
}

\author{
Hiroaki Tanabe $\cdot$ Kanna Motoyama $\cdot$ Mariko Ikeda $\cdot$ Motoaki Wakiyama $\cdot$ \\ Takaho Terada $\cdot$ Noboru Ohsawa $\cdot$ Toshiaki Hosaka $\cdot$ Masakatsu Hato • \\ Yoshifumi Fujii · Yoshihiro Nakamura - Satoshi Ogasawara • Tomoya Hino • \\ Takeshi Murata $\cdot$ So Iwata $\cdot$ Miki Okada-Iwabu $\cdot$ Masato Iwabu • \\ Kunio Hirata · Yoshiaki Kawano - Masaki Yamamoto - Tomomi Kimura-Someya • \\ Mikako Shirouzu • Toshimasa Yamauchi - Takashi Kadowaki - Shigeyuki Yokoyama
}

Received: 18 September 2014/ Accepted: 19 November 2014/Published online: 10 January 2015

(C) The Author(s) 2015. This article is published with open access at Springerlink.com

\begin{abstract}
The adiponectin receptors (AdipoR1 and AdipoR2) are membrane proteins with seven transmembrane helices. These receptors regulate glucose and fatty acid metabolism, thereby ameliorating type 2 diabetes. The fulllength human AdipoR1 and a series of N-terminally truncated mutants of human AdipoR1 and AdipoR2 were expressed in insect cells. In small-scale size exclusion chromatography, the truncated mutants AdipoR $1 \Delta 88$ (residues 89-375) and AdipoR2 $\Delta 99$ (residues 100-386) eluted
\end{abstract}

H. Tanabe $\cdot$ K. Motoyama $\cdot$ M. Ikeda $\cdot$ M. Wakiyama .

T. Terada $\cdot$ N. Ohsawa $\cdot$ T. Hosaka $\cdot$ M. Hato $\cdot$ Y. Fujii ·

Y. Nakamura $\cdot$ T. Murata $\cdot$ S. Iwata $\cdot$ T. Kimura-Someya

M. Shirouzu $\cdot$ S. Yokoyama $(\square)$

RIKEN Systems and Structural Biology Center, 1-7-22 Suehiro-

cho, Tsurumi-ku, Yokohama 230-0045, Japan

e-mail: yokoyama@ riken.jp

H. Tanabe $\cdot$ S. Yokoyama

Department of Biophysics and Biochemistry and Laboratory of Structural Biology, Graduate School of Science, The University of Tokyo, Hongo, Bunkyo-ku, Tokyo 113-0033, Japan

H. Tanabe - M. Ikeda $\cdot$ M. Wakiyama - N. Ohsawa - T. Hosaka M. Hato · Y. Nakamura - T. Kimura-Someya · M. Shirouzu Division of Structural and Synthetic Biology, RIKEN Center for Life Science Technologies, 1-7-22 Suehiro-cho, Tsurumi-ku, Yokohama 230-0045, Japan

T. Terada $\cdot$ Y. Fujii $\cdot$ S. Yokoyama

RIKEN Structural Biology Laboratory, 1-7-22 Suehiro-cho,

Tsurumi-ku, Yokohama 230-0045, Japan

S. Ogasawara $\cdot$ T. Hino $\cdot$ T. Murata $\cdot$ S. Iwata

Department of Cell Biology, Graduate School of Medicine,

Kyoto University, Yoshida-Konoe-cho, Sakyo-ku,

Kyoto 606-8501, Japan mostly in the intact monodisperse state, while the others eluted primarily as aggregates. However, gel filtration chromatography of the large-scale preparation of the tagaffinity-purified AdipoR1 $\Delta 88$ revealed the presence of an excessive amount of the aggregated state over the intact state. Since aggregation due to contaminating nucleic acids may have occurred during the sample concentration step, anion-exchange column chromatography was performed immediately after affinity chromatography, to separate the intact AdipoR1 $\Delta 88$ from the aggregating species. The

T. Hino $\cdot$ T. Murata $\cdot$ S. Iwata

JST, Research Acceleration Program, Membrane Protein

Crystallography Project, Yoshida-Konoe-cho, Sakyo-ku,

Kyoto 606-8501, Japan

T. Murata

Department of Chemistry, Graduate School of Science, Chiba

University, Yayoi-cho, Inage, Chiba 263-8522, Japan

S. Iwata

Division of Molecular Biosciences, Membrane Protein

Crystallography Group, Imperial College, London SW7 2AZ, UK

S. Iwata

Diamond Light Source, Harwell Science and Innovation

Campus, Chilton, Didcot, Oxfordshire OX11 0DE, UK

S. Iwata $\cdot$ K. Hirata $\cdot$ Y. Kawano $\cdot$ M. Yamamoto RIKEN SPring-8 Center, Harima Institute, Kouto, Sayo, Hyogo 679-5148, Japan

M. Okada-Iwabu $\cdot$ M. Iwabu $\cdot$ T. Yamauchi $(\bowtie)$.

T. Kadowaki $(\square)$

Department of Diabetes and Metabolic Diseases, Graduate

School of Medicine, The University of Tokyo, Hongo,

Bunkyo-ku, Tokyo 113-0033, Japan

e-mail: tyamau-tky@umin.net 
separated intact AdipoR1 $\Delta 88$ did not undergo further aggregation, and was successfully purified to homogeneity by gel filtration chromatography. The purified AdipoR1 $\Delta 88$ and AdipoR2 $\Delta 99$ proteins were characterized by thermostability assays with 7-diethylamino-3-(4-maleimidophenyl)-4-methyl coumarin, thin layer chromatography of bound lipids, and surface plasmon resonance analysis of ligand binding, demonstrating their structural integrities. The AdipoR1 $\Delta 88$ and AdipoR2 $\Delta 99$ proteins were crystallized with the anti-AdipoR1 monoclonal antibody Fv fragment, by the lipidic mesophase method. X-ray diffraction data sets were obtained at resolutions of 2.8 and $2.4 \AA$ A, respectively.

Keywords Membrane protein - Adiponectin receptors AdipoR1 and AdipoR2 - Purification - Antibody . Crystallization · Lipidic mesophase

\section{Introduction}

Adiponectin is an anti-diabetic and anti-atherogenic adipokine, and is exclusively expressed in adipose tissue [1-4]. Serum adiponectin levels are significantly reduced in patients with obesity, metabolic syndrome, and type 2 diabetes [5]. We previously reported the expression cloning of complementary DNAs encoding adiponectin receptors (Adipor) 1 and 2 [6]. These adiponectin receptors, AdipoR1 and AdipoR2, are key membrane proteins that exert anti-metabolic syndrome effects. Adiponectin accomplishes its biological effects by binding to the AdipoR1 and AdipoR2 receptors. In the liver, both adiponectin receptors mediate the major part of the insulin-sensitizing actions of adiponectin, while AdipoR1 primarily does so in skeletal muscle. AdipoR1 and AdipoR2 regulate glucose and fatty acid metabolism partly via the activation of the AMPK [7-9], $\mathrm{Ca}^{2+}$ [10], and PPAR $\alpha[11,12]$ signaling pathways. Interestingly,

T. Kadowaki

e-mail: kadowaki-3im@h.u-tokyo.ac.jp

M. Okada-Iwabu - M. Iwabu - T. Yamauchi - T. Kadowaki Department of Integrated Molecular Science on Metabolic Diseases, 22nd Century Medical and Research Center, The University of Tokyo, Hongo, Bunkyo-ku, Tokyo 113-0033, Japan

\section{Iwabu}

PRESTO, Japan Science and Technology Agency, Kawaguchi, Saitama 332-0012, Japan

T. Yamauchi

CREST, Japan Science and Technology Agency, Kawaguchi,

Saitama 332-0012, Japan
AdipoR1 and AdipoR2 are predicted to contain seventransmembrane domains [6], but they are structurally distinct from G-protein coupled receptors (GPCRs) [13]. The adiponectin receptors possess an internal $\mathrm{N}$-terminus and an external C-terminus, which is opposite to the topology of GPCRs. Therefore, AdipoRs are predicted to have unique structures, as compared to those of GPCRs.

Here, we report the expression and purification of the $\mathrm{N}$-terminally truncated human AdipoR1 and AdipoR2 proteins, crystallization of the truncated AdipoR1 and AdipoR2 in complexes with the $\mathrm{Fv}$ fragment of an antiAdipoR1 monoclonal antibody, and their preliminary X-ray crystallographic studies.

\section{Materials and methods}

Plasmid construction

The $B g l$ III-FLAG-TEV-BamHI-EcoRI DNA (5'-GGAAGA TCTATGGATTACAAGGACGACGACGATAAGGAAA ACCTGTATTTTCAGGGCGGATCCGAATTCCCG-3') and its complementary DNA were synthesized, annealed together, digested with $B g l I I$ and EcoRI, and subcloned into the BamHI and EcoRI sites of pFastBac1. The resulting plasmid encodes a Flag tag followed by a TEV cleavage site at the $\mathrm{N}$-terminus, and is referred to as pFastBac1-FT hereafter. The cDNAs encoding the fulllength human AdipoR1 (residues 1-375) and N-terminally-truncated mutants of AdipoR1 and AdipoR2 (AdipoR1 $\Delta 46$, residues $47-375 ; \Delta 76,77-375 ; \Delta 88,89-375$; $\Delta 101,102-375$; and $\Delta 119,120-375$; AdipoR2 $\Delta 58$, residues 59-386; $\Delta 87, \quad 88-386 ; \quad \Delta 99, \quad 100-386 ; \quad \Delta 112$, $113-386$; and $\Delta 130,131-386)$ were amplified by PCR. The PCR products were digested with $B a m \mathrm{HI}$ and XhoI for AdipoR1 and EcoRI and XhoI for AdipoR2, and then inserted into the pFastBac1-FT vector.

\section{Protein expression in insect cells}

High-titer recombinant baculoviruses were obtained with the Bac-to-Bac Baculovirus Expression System (Invitrogen), according to the manufacturer's protocol. For largescale and small-scale production of the recombinant proteins, Trichoplusia ni (High Five) cells, at densities of $2 \times 10^{6}$ and $2-5 \times 10^{6}$ cell $/ \mathrm{ml}$, respectively, were infected with the high-titer viral stock at a multiplicity of infection (m.o.i.) of 0.5. Cells were harvested by centrifugation at 42-h post infection, and were washed once with phosphate buffer saline (PBS). Cells were flash-frozen in liquid nitrogen, and stored at $-80{ }^{\circ} \mathrm{C}$ until use. 
Large-scale membrane preparation

For large-scale preparations of the full-length AdipoR1, AdipoR $1 \Delta 88$, and AdipoR $2 \Delta 99$ proteins, frozen cells were thawed in high osmotic buffer [10 mM HEPES-NaOH buffer (pH 7.4) containing $1.0 \mathrm{M} \mathrm{NaCl}, 10 \mathrm{mM} \mathrm{MgCl}$, $20 \mathrm{mM} \mathrm{KCl}$, and EDTA-free Complete Protease Inhibitor Cocktail (Roche)], and disrupted by Dounce homogenization. The raw membranes were collected by ultracentrifugation at $100,000 \times g$ for $30 \mathrm{~min}$, and were resuspended in high osmotic buffer. These ultracentrifugation and resuspension steps were repeated four times, to remove the peripheral membrane proteins. Finally, the washed membranes were resuspended in $20 \mathrm{mM}$ HEPES-NaOH buffer (pH 7.4) containing $100 \mathrm{mM} \mathrm{NaCl}$ and $10 \%(\mathrm{v} / \mathrm{v})$ glycerol, flash-frozen with liquid nitrogen, and stored at $-80{ }^{\circ} \mathrm{C}$ until use. The membrane proteins were quantified with the $D C$ Protein Assay (Bio-Rad), using bovine serum albumin (BSA) as the standard.

\section{Large-scale protein purification}

The purified membranes $(20 \mathrm{mg} / \mathrm{ml}$ of total membrane proteins) were solubilized with $20 \mathrm{mM}$ HEPES-NaOH buffer ( $\mathrm{pH}$ 7.4) containing $100 \mathrm{mM} \mathrm{NaCl}, 10 \%$ (v/v) glycerol, and $1 \%$ (w/v) $n$-dodecyl- $\beta$-D-maltoside (DDM, Anatrace), for $1-2 \mathrm{~h}$ at $4{ }^{\circ} \mathrm{C}$. The insoluble materials were removed by ultracentrifugation at $100,000 \times g$ for $1 \mathrm{~h}$. The supernatant was filtered $(0.45 \mu \mathrm{m})$ and incubated with Anti DYKDDDDK Tag Antibody Beads (Wako) in $20 \mathrm{mM}$ HEPES-NaOH buffer (pH 7.4) containing $300 \mathrm{mM} \mathrm{NaCl}, 10 \%(\mathrm{v} / \mathrm{v})$ glycerol, and $0.5 \%(\mathrm{w} / \mathrm{v})$ $\mathrm{DDM}$, at $4{ }^{\circ} \mathrm{C}$ with gentle agitation. The beads were washed with thirty column volumes of buffer A [20 mM HEPES-NaOH buffer (pH 7.4), containing $10 \%(\mathrm{v} / \mathrm{v})$ glycerol, $0.025 \%(\mathrm{w} / \mathrm{v}) \mathrm{DDM}$, and $0.0001 \%(\mathrm{w} / \mathrm{v})$ cholesteryl-hemi-succinate (CHS, Anatrace)], containing $200 \mathrm{mM} \mathrm{NaCl}$. Then, the adsorbed AdipoR1/AdipoR2 proteins were eluted with five column volumes of buffer A containing 100 or $200 \mathrm{mM} \mathrm{NaCl}$ and $0.1 \mathrm{mg} / \mathrm{ml} \mathrm{DY-}$ KDDDDK peptide (Wako). Further purification was performed by the following three methods.

First, the affinity-purified sample was concentrated by ultrafiltration with an Ultra-15 30 K-MWCO filter (Millipore), and then loaded on a HiLoad 16/600 Superdex 200 (GE Healthcare) column equilibrated in buffer A containing $200 \mathrm{mM} \mathrm{NaCl}$. Second, the affinity-purified sample, in $100 \mathrm{mM} \mathrm{NaCl}$, was loaded on a 1-ml HiTrap Q column (GE Healthcare) equilibrated with buffer A containing $100 \mathrm{mM} \mathrm{NaCl}$, and was eluted by a $100-1,000 \mathrm{mM}$ linear $\mathrm{NaCl}$ gradient in buffer $\mathrm{A}$. The sample was further purified by SEC on a Superdex 200
10/300 (GE Healthcare) column, in buffer A containing $200 \mathrm{mM} \mathrm{NaCl}$. Third, the affinity-purified sample, in $200 \mathrm{mM} \mathrm{NaCl}$, was loaded on a 1-ml HiTrap Q column equilibrated with buffer A containing $200 \mathrm{mM} \mathrm{NaCl}$, and the flow-through fraction was collected. The polyhistidine-tagged TEV protease was added to the anionexchange-purified fraction, and incubated with the receptor overnight at $4{ }^{\circ} \mathrm{C}$. The receptor was separated from TEV by adsorption to TALON resin (Clontech), and was further purified by SEC on a Superdex 200 10/300 column in buffer A containing $200 \mathrm{mM} \mathrm{NaCl}$. The purities of the AdipoR1 $\Delta 88$ and AdipoR2 $\Delta 99$ proteins were assessed by SDS-PAGE.

\section{Small-scale SEC analysis}

Frozen cells were thawed in the high osmotic buffer, and then sonicated to disrupt the cells. The membranes were collected by ultracentrifugation at $100,000 \times g$ for $15 \mathrm{~min}$, and were resuspended in $20 \mathrm{mM}$ HEPES-NaOH buffer (pH 7.4) containing $150 \mathrm{mM} \mathrm{NaCl}, 1 \mathrm{mM}$ EDTA, and $5 \mathrm{mM} \mathrm{MgCl} 2$. The purified membranes $(10 \mathrm{mg} / \mathrm{ml}$ of membrane protein) were solubilized with $20 \mathrm{mM}$ HEPES-NaOH buffer ( $\mathrm{pH}$ 7.4) containing $1 \%(\mathrm{w} / \mathrm{v})$ DDM, $150 \mathrm{mM} \mathrm{NaCl}, 1 \mathrm{mM}$ EDTA, and $5 \mathrm{mM} \mathrm{MgCl}$, for $1 \mathrm{~h}$ at $4{ }^{\circ} \mathrm{C}$. The insoluble material was removed by ultracentrifugation at $100,000 \times g$ for $30 \mathrm{~min}$. The supernatant was incubated with $100 \mu \mathrm{l}$ anti-FLAG M2 affinity gel (Sigma) in $20 \mathrm{mM}$ HEPES-NaOH buffer (pH 7.4) containing $150 \mathrm{mM} \mathrm{NaCl}, 1 \mathrm{mM}$ EDTA, $5 \mathrm{mM} \mathrm{MgCl}$, $5 \%(\mathrm{v} / \mathrm{v})$ glycerol, and $0.5 \%(\mathrm{w} / \mathrm{v}) \mathrm{DDM}$, at $4{ }^{\circ} \mathrm{C}$ with gentle agitation. The beads were washed with five column volumes of $20 \mathrm{mM}$ HEPES-NaOH buffer ( $\mathrm{pH} 7.4$ ) containing $150 \mathrm{mM} \mathrm{NaCl}, 1 \mathrm{mM}$ EDTA, $5 \mathrm{mM} \mathrm{MgCl}$, $5 \%(\mathrm{v} / \mathrm{v})$ glycerol, and $0.04 \%(\mathrm{w} / \mathrm{v}) \mathrm{DDM}$, and the adsorbed receptor was eluted with five column volumes of the same buffer containing $0.1 \mathrm{mg} / \mathrm{ml}$ FLAG peptide (Sigma). The affinity purified sample was then loaded on a Superdex $20010 / 300$ column in $20 \mathrm{mM}$ HEPES-NaOH buffer ( $\mathrm{pH}$ 7.4) containing $200 \mathrm{mM} \mathrm{NaCl}, 10 \%$ (v/v) glycerol, and $0.04 \%(\mathrm{w} / \mathrm{v})$ DDM. Fractions $(1 \mathrm{ml})$ were collected. Portions $(5 \mu \mathrm{l})$ of the eluates were separated by SDS-PAGE, and transferred to a PVDF membrane. The membranes were blocked in $5 \%(\mathrm{w} / \mathrm{v})$ dry milk in TBS-T buffer [Tris-buffered saline, $0.1 \%(\mathrm{v} / \mathrm{v})$ Tween20] at room temperature for $1 \mathrm{~h}$. The blocked membranes were detected with the anti-FLAG M2 monoclonal antibody (Sigma) and the anti-mouse IgG, HRP-linked whole antibody from sheep (GE Healthcare) in TBS-T buffer. The membranes were visualized using Immobilon Western Chemiluminescent HRP Substrate (Millipore), and detected with an LAS3000 imager (Fuji). 
Characterization of the purified $\mathrm{N}$-terminally truncated mutants of AdipoR1 and AdipoR2

The purified AdipoR $1 \Delta 88$ and AdipoR $2 \Delta 99$ proteins were analyzed by the following three methods. First, the thermal stabilities of AdipoR1 $\Delta 88$ and AdipoR2 $\Delta 99$ were analyzed by the 7-diethylamino-3-(4-maleimidophenyl)-4-methyl coumarin (CPM) assay method $[14,15]$. The fluorescence of the CPM dye was measured with a 340-nm excitation filter with a 10-nm bandpass and a 460-nm emission filter with a $35-\mathrm{nm}$ bandpass at $40{ }^{\circ} \mathrm{C}$, on a FUSION $\alpha$ Microplate Reader PerkinElmer. Second, the lipids that co-purified with the AdipoR $1 \Delta 88$ and AdipoR $2 \Delta 99$ proteins were analyzed by thin layer chromatography (TLC). The fulllength AdipoR1 and AdipoR2, prepared by FLAG affinity and anion-exchange chromatography, were also analyzed for comparison. The proteins were dissolved in chloroform/ methanol $[2: 1(\mathrm{v} / \mathrm{v})]$, and the bound lipids were extracted from the proteins. The extracted samples were applied to a silica gel 60 TLC plate (Merck Millipore), which was then developed by a solvent system composed of chloroform/ methanol/water [65:25:4 (v/v)]. The lipids were visualized with acetic acid/sulfuric acid [1:1 (v/v)], the phosphomolybdic reagent (Pierce), and the ninhydrin reagent (Wako). Third, the ligand-binding activity of AdipoR $1 \Delta 88$ was measured by surface plasmon resonance (SPR) measurements. The purified AdipoR $1 \Delta 88$ was reconstituted into liposomes $[5 \mathrm{mg} / \mathrm{ml}$ egg yolk phosphatidylcholine (PC) (Avanti Polar Lipids Inc.) and $0.05 \mathrm{mg} / \mathrm{ml}$ biotinyl-phosphatidylethanolamine (biotinyl-PE) (Avanti Polar Lipids Inc.)], and the reconstituted liposomes were immobilized onto a sensor chip SA. Binding analyses were performed with a range of osmotin concentrations $(0.5-8 \mu \mathrm{M})$ on a Biacore T200 (GE Healthcare).

Production of the anti-AdipoR1 monoclonal antibody

All animal experiments described here were approved by the Institutional Animal Care and Use Committee of Kyoto University Graduate School of Medicine. The purified untagged AdipoR1 $\Delta 88$ was reconstituted into liposomes [5 mg/ml egg yolk PC and $1 \mathrm{mg} / \mathrm{ml}$ lipid A (Sigma)]. Female BALB/c mice were immunized five times with $0.1 \mathrm{mg}$ doses of the reconstituted AdipoR1 $\Delta 88$, at intervals of 10 days. Single-cell suspensions were prepared from the spleens of the immunized mice, and the cells were fused with P3U1 myeloma cells, using the conventional polyethylene glycol (PEG) method [16]. Screening of antibodies was performed by three methods, enzyme-linked immunosorbent assay (ELISA), fluorescence-detection SEC (FSEC), and denatured dot blot assays [17, Ogasawara et al., manuscript in preparation]. For ELISA, the purified AdipoR1 $\Delta 88$ was reconstituted into liposomes containing
biotinyl-PE, and was immobilized on Immobilizer Streptavidin plates (Nunc). High-affinity antibodies that formed stable complexes with the purified AdipoR1 $\Delta 88$ were selected by FSEC, using the fluorescein-conjugated Fab fragment of an anti-mouse IgG (Jackson), on a Superdex 200 5/150 column (GE Healthcare). Antibodies that recognized the native conformation of AdipoR1 $\Delta 88$ were selected by dot blot assays with SDS-denatured AdipoR1 $\Delta 88$. Each selected clone was isolated by the limiting dilution-culture method, and monoclonal hybridoma cell lines producing anti-AdipoR1 $\Delta 88$ antibodies were established.

Recombinant production of the Fv fragment of the antiAdipoR1 antibody

The sequences of the $\mathrm{V}_{\mathrm{H}}$ and $\mathrm{V}_{\mathrm{L}}$ regions were determined by the standard method, with total RNA isolated from the hybridoma cells [18]. The cloned $\mathrm{V}_{\mathrm{H}}$ and $\mathrm{V}_{\mathrm{L}}$ cDNA fragments were subcloned into the TA-cloning vector, pCR2.1 TOPO (Invitrogen) [19], encoding a fusion protein with an N-terminal His-tag, a SUMO tag, and a SUMO protease cleavage site. The $\mathrm{V}_{\mathrm{H}}$ and $\mathrm{V}_{\mathrm{L}}$ fragments were co-synthesized by the E. coli cell-free protein synthesis method [20], supplemented with DsbC and the reduced and oxidized forms of glutathione (GSH and GSSG, respectively) to form disulfide bonds [21]. The reaction solution was centrifuged at $20,000 \times g$ and $4{ }^{\circ} \mathrm{C}$ for $10 \mathrm{~min}$. The supernatant was loaded on a 1-ml HisTrap column (GE Healthcare) equilibrated with $20 \mathrm{mM}$ Tris- $\mathrm{HCl}$ buffer ( $\mathrm{pH}$ 8.0) containing $500 \mathrm{mM} \mathrm{NaCl}$ and $20 \mathrm{mM}$ imidazole, and was eluted by a $20-500 \mathrm{mM}$ linear gradient of imidazole in $20 \mathrm{mM}$ Tris- $\mathrm{HCl}$ buffer ( $\mathrm{pH}$ 8.0) containing $500 \mathrm{mM}$ $\mathrm{NaCl}$. The His- and SUMO-tags were cleaved by SUMO protease for 2-3 days at room temperature, and were removed by a second passage through the HisTrap column. The protein sample was then loaded on a HiLoad 16/600 Superdex 200 column, equilibrated in $20 \mathrm{mM}$ HEPES$\mathrm{NaOH}$ buffer ( $\mathrm{pH}$ 7.4) containing $200 \mathrm{mM} \mathrm{NaCl}$. The purified $\mathrm{Fv}$ fragment (Fv43) was concentrated to approximately $20 \mathrm{mg} / \mathrm{ml}$, by ultrafiltration with an Ultra-15 $10 \mathrm{~K}$ MWCO filter (Millipore).

Preparation of the AdipoR1.Fv43 and AdipoR2.Fv43 complexes

The Fv43 (24.8 kDa) was mixed with the purified FLAGtagged AdipoR1 $\Delta 88(35.0 \mathrm{kDa})$ or untagged AdipoR2 $\Delta 99$ $(32.9 \mathrm{kDa})$, and incubated on ice for $30 \mathrm{~min}$. The mixture was loaded onto a Superdex 200 10/300 column equilibrated with $20 \mathrm{mM}$ HEPES-NaOH buffer (pH 7.4) containing $200 \mathrm{mM} \mathrm{NaCl}, 0.025 \%$ (w/v) DDM, and $0.0001 \%$ (w/v) CHS, and was eluted using the same buffer. Fractions 


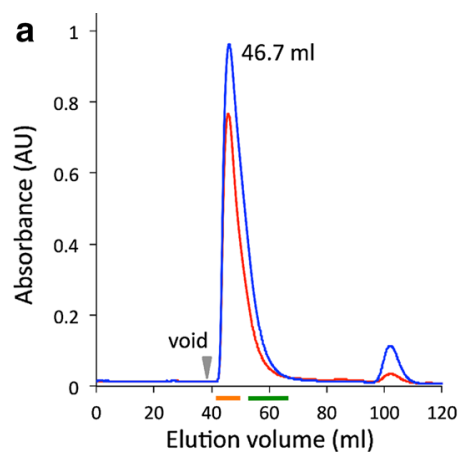

Fig. 1 Purification of full-length AdipoR1. a Gel filtration chromatogram of the full-length AdipoR1 expressed in High Five insect cells. The proteins were purified by FLAG-affinity chromatography, and then loaded onto a HiLoad 16/600 Superdex 200 column. The main peak retention volume is labeled in black $(46.7 \mathrm{ml})$. The absorbances at 280 and $254 \mathrm{~nm}$ are colored blue and red,

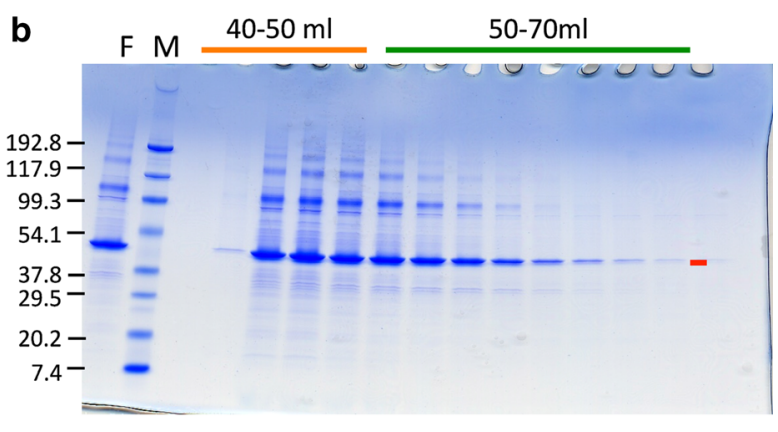

respectively. b SDS-PAGE analysis of the gel-filtration chromatographic fractions containing the full-length AdipoR1. Fractions indicated by the orange and green lines along the horizontal axis in a were analyzed by SDS-PAGE. Lane $F$, the eluate from FLAGaffinity chromatography; Lane $M$, molecular-weight markers (kDa) a

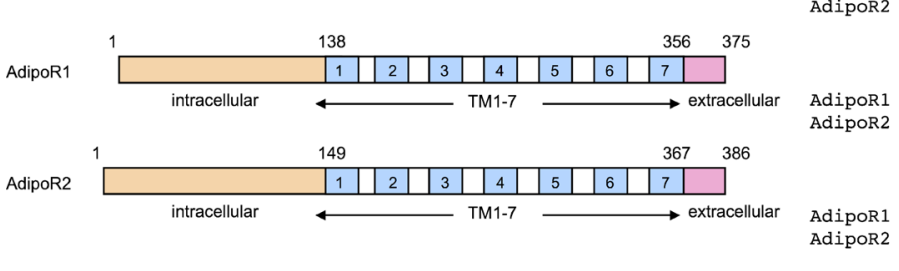

47

----------MSSHKGSVVAQGNGAPASNREADTVELAELGPLLEEKGKRVIANPPKA 48 MNEPTENRLGCSRTPEPDIRLRKGHQLDGTRRGDNDSHQGDLEPILEASVLSSHHKKSSE 60 $: . .:::^{*}::^{*}:$ : . : **:**. : .

$$
\begin{array}{llll}
77 & 89 & 102 \quad 58
\end{array}
$$

EEEQTCPVPOEEEEEVRVLTLPLQAHHAMEKMEEFVYKVWEGRWRVIPYDVLPDWLKDND 108 EHEYSDEAPQEDEG-FMGMSPLLQAHHAMEKMEEFVCKVWEGRWRVIPHDVLPDWLKDND 119 $* *: . * * * *$ : : : $: * * * * * * * * * * * * * * * * * * * * * * *: * * * * * * * * * * *$

$$
\begin{array}{rrrr}
120 & 1 & 1 & 1 \\
128 & 100 & 113
\end{array}
$$

YLLHGHRPPMPSFRACFKSIFRIHTETGNIWTHLLGFVLFLFLGILTMLRPNMYFMAPLQ 168 FLLHGHRPPMPSFRACFKS IFR IHTETGNIWTHLLGCVFFLCLGIFYMFRPNISFVAPLQ 179 $: * * * * * * * * * * * * * * * * * * * * * * * * * * * * * * * * * * * *: * * * * *: * ;: * * *: *: * * * *$ 131

C
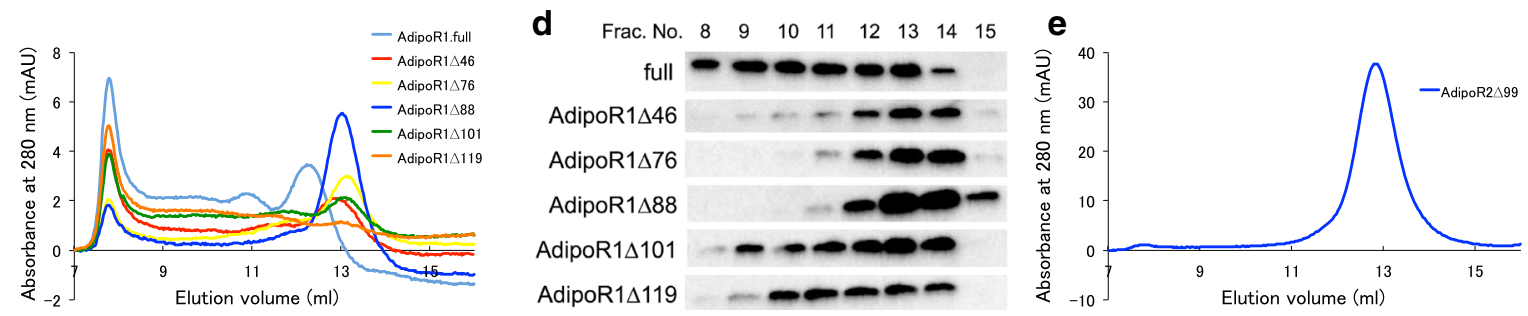

Fig. 2 Screening of the N-terminally truncated mutants of AdipoR1 and AdipoR2. Several N-terminal deletion mutants were analyzed by size-exclusion chromatography. a Schematic representations of human AdipoR1 (top) and AdipoR2 (bottom). b Amino acid sequences of the N-terminal regions of human AdipoR1 and AdipoR2. The starting amino acid residues of the N-terminally truncated mutants of AdipoR1 and AdipoR2 are numbered in red.

containing the complex were collected and concentrated to approximately $15 \mathrm{mg} / \mathrm{ml}$ by ultrafiltration (Ultra- $430 \mathrm{~K}$ MWCO, Millipore). The purities of the AdipoR1 $\Delta 88 \cdot$ Fv 43 and AdipoR2 $\Delta 99 \cdot$ Fv 43 complexes were assessed by SDSPAGE.

\section{Crystallization and X-ray data collection}

The purified AdipoR1 $\Delta 88 \cdot \mathrm{Fv} 43$ and AdipoR2 $\Delta 99 \cdot \mathrm{Fv} 43$ complexes were reconstituted into a lipidic mesophase, by mixing with molten lipid in a mechanical syringe mixer [22]. The protein-LCP mixture contained $40 \%(\mathrm{w} / \mathrm{w})$ protein solution, $54 \%(\mathrm{w} / \mathrm{w})$ monoolein (Sigma) and $6 \%(\mathrm{w} / \mathrm{w})$
Amino acids in putative transmembrane domains are shown in gray letters. The sequences were aligned with ClustalW [38]. c Sizeexclusion chromatograms of the full-length form and the N-terminally truncated mutants of AdipoR1. d Detection of the AdipoR1 protein in the size-exclusion chromatography fractions by western blotting with the anti-FLAG M2 antibody. e Size-exclusion chromatogram of AdipoR2 $\Delta 99$

cholesterol (Sigma). Forty nanoliter drops of the resulting lipidic mesophase sample were dispensed into 96 well glass plates, overlaid with $0.8 \mu \mathrm{l}$ precipitant solution, and covered with thin cover glasses, by the use of laboratory-constructed manual and robotic micro-dispensers [23, Hato et al., manuscript in preparation]. Crystallization setups were performed at room temperature, and the plates were incubated at $20{ }^{\circ} \mathrm{C}$. Crystals were harvested directly from the lipidic mesophase using MiTeGen micromounts, and flash cooled in liquid nitrogen. Data collection was performed on beamline BL32XU at SPring-8, using an MX225HE CCD detector [24-26]. X-ray diffraction data with a micro beam of $1 \mu \mathrm{m} \times 10 \mu \mathrm{m}$ (horizontal $\times$ vertical) were collected at 
$100 \mathrm{~K}$, by the helical scan method with $1^{\circ}$ oscillation. The data from the AdipoR1 $\Delta 88 \cdot \mathrm{Fv} 43$ and AdipoR2 $\Delta 99 \cdot \mathrm{Fv} 43$ crystals were indexed, scaled, and merged with the HKL2000 program suite [27] and the XDS package [28], respectively.

\section{Results and discussion}

Screening of deletion mutants of AdipoR1 and AdipoR2

The full-length AdipoR1 (residues 1-375) was expressed in baculovirus-infected High Five insect cells, and the membrane fractions were prepared. Upon gel filtration chromatography (size-exclusion chromatography, SEC) on a HiLoad 16/600 Superdex 200 column, the detergent-solubilized full-length AdipoR1 mainly eluted just after the void volume $(40 \mathrm{ml})$ (Fig. 1). If the full-length AdipoR1 was monomeric and monodisperse, then the proteomicelle should exhibit an estimated molecular mass of ca. $125 \mathrm{kDa}$ (the full-length AdipoR1 monomer, $44.7 \mathrm{kDa}$; DDM micelle, ca. $80 \mathrm{kDa}$ ), and elute after $55 \mathrm{ml}$ (the elution volume of ferritin, $440 \mathrm{kDa}$ ) on the gel filtration column. However, most of the full-length AdipoR1 eluted before $55 \mathrm{ml}$ (Fig. 1), indicating that this sample was highly polydisperse and not suitable for crystallization.

We therefore tried to modify the AdipoR1 construct. Prediction servers of protein secondary structure, PSIPRED v3.3 [29], and transmembrane domains, HMMTOP [30], suggested that human AdipoR1 and AdipoR2 have a long $\mathrm{N}$-terminal region, seven transmembrane (TM) helices with short loops connecting the TM helices, and a short C-terminal region (Fig. 2a). Since more than $50 \%$ of the $\mathrm{N}$-terminal region was predicted to be flexible, we speculated that this long $\mathrm{N}$-terminal tail is related to the observed polydispersity of AdipoR1 (Fig. 1).

Therefore, we constructed a series of N-terminallydeleted mutants of AdipoR1 (Fig. 2b). They were expressed on a small scale, and were analyzed by SEC without concentration. In this small-scale SEC analysis of AdipoR1 (Fig. 2c, d), the non-concentrated sample of the full-length AdipoR1 was less aggregated, as compared with the concentrated sample in the large-scale preparation, because it exhibited a small peak eluting at ca. $13 \mathrm{ml}$ (Fig. 1). This ca. 13-ml elution volume in the small-scale SEC analysis should correspond to ca. $65 \mathrm{ml}$ in the large-scale gel filtration chromatography. Deletions of residues 1-46 $(\Delta 46)$ and 1-76 $(\Delta 76)$ of AdipoR1 significantly increased the fraction eluting at ca. $13 \mathrm{ml}$, as compared with the fulllength AdipoR1. However, the total amounts of these deletion mutants were much lower than that of the fulllength AdipoR1 obtained from the same amount of cells.
Fig. 3 Large-scale preparation of FLAG-tagged AdipoR1 $\Delta 88$ and AdipoR2 $\Delta 99$ expressed in High Five cells. In the chromatograms (a, $\mathbf{c}-\mathbf{h}, \mathbf{j}, \mathbf{k}, \mathbf{m}, \mathbf{n})$, the absorbances at 280 and $254 \mathrm{~nm}$, and the $\mathrm{NaCl}$ concentration are shown in blue, red, and light green, respectively. a Gel filtration chromatogram of FLAG-tagged AdipoR1 $\Delta 88$ expressed in High Five insect cells. The proteins were purified by FLAG-affinity chromatography, and then chromatographed on a HiLoad 16/600 Superdex 200 column. The main peak elution volume is labeled in black $(58.8 \mathrm{ml})$. b SDS-PAGE analysis of the gelfiltration chromatographic fractions containing the FLAG-tagged AdipoR $1 \Delta 88$. Fractions indicated by the orange and green lines along the horizontal axis in a were analyzed by SDS-PAGE. Lane $M$, molecular-weight markers ( $\mathrm{kDa})$. c Anion-exchange chromatogram of the FLAG-tagged AdipoR1 $\Delta 88$, with isocratic elution by $100 \mathrm{mM}$ $\mathrm{NaCl}$ in buffer $\mathrm{A}$, and subsequently with gradient elution by $100-1,000 \mathrm{mM} \mathrm{NaCl}$ in buffer A. d, e Gel filtration chromatograms of the peak 1 (d) and peak 2 (e) fractions, indicated by the orange and green lines in $\mathbf{c}$, respectively. $\mathbf{f}$ Anion-exchange chromatogram of the FLAG-tagged AdipoR1 $\Delta 88$, with isocratic elution by $200 \mathrm{mM} \mathrm{NaCl}$ in buffer A, and subsequently with gradient elution by $200-1,000 \mathrm{mM}$ $\mathrm{NaCl}$ in buffer A. $\mathbf{g}$, h Gel filtration chromatograms of the flowthrough (g) and adsorbed (h) fractions, indicated by the orange and green lines in $\mathbf{f}$, respectively. i SDS-PAGE analysis of the FLAGtagged AdipoR1 $\Delta 88$. Lane $M$, molecular-weight markers $(\mathrm{kDa})$; lane 1 , the membrane fraction; lane 2, DDM-solubilized membrane proteins in the supernatant after ultracentrifugation; lane 3, the flow-through fraction from FLAG-affinity chromatography; lane 4, the eluate from FLAG-affinity chromatography; lane 5, the flowthrough fraction from anion-exchange chromatography (f); lanes 6-9, the peak fractions of the FLAG-tagged AdipoR $1 \Delta 88$ from gel filtration chromatography (g). j Anion-exchange chromatogram of AdipoR2 299 , with isocratic elution by $200 \mathrm{mM} \mathrm{NaCl}$ in buffer $\mathrm{A}$ and subsequently with gradient elution by $200-1,000 \mathrm{mM} \mathrm{NaCl}$ in buffer A. $\mathbf{k}$ Gel filtration chromatogram of the flow-through fractions indicated by the orange line in $\mathbf{j}$. I SDS-PAGE analysis of AdipoR2 $\Delta 99$. Lane $M$, molecular-weight markers (kDa); lane 1 , the membrane fraction; lane 2, DDM-solubilized membrane proteins in the ultracentrifugation supernatant; lane 3, the flow-through fraction from FLAG-affinity chromatography; lane 4, the eluate from FLAGaffinity chromatography; lane 5, the flow-through fraction from anion-exchange chromatography after the TEV protease digestion; lane 6 , the flow-through fraction from TALON chromatography; lanes $7-11$, the peak fractions of AdipoR $2 \Delta 99$ from gel filtration chromatography. $\mathbf{m}, \mathbf{n}$ Gel filtration chromatographic analysis of the purified FLAG-tagged AdipoR1 $\Delta 88$ (m) and the purified AdipoR2 499 (n)

By contrast, the deletion of residues $1-88(\Delta 88)$ of AdipoR1 further improved the monodispersity in the SEC analysis, and the total amount of this deletion mutant protein was as high as that of the full-length AdipoR1 (Fig. 2c, d). On the other hand, further deletion mutants (AdipoR1 $\Delta 101$ and AdipoR1 $\Delta 119$ ) were less aggregated than the full-length protein, but appreciably more aggregated than AdipoR1 $\Delta 88$. Thus, we concluded that the AdipoR1 $\Delta 88$ mutant was the best among the tested deletion mutants. The screening of AdipoR2 $\Delta 58, \Delta 87, \Delta 99$, $\Delta 112$, and $\Delta 130$ was performed in the same manner, and AdipoR2 $\Delta 99$ was found to be the best (Fig. 2e). Consequently, the AdipoR1 $\Delta 88$ and AdipoR2 $\Delta 99$ mutants were selected and used for further crystallization trials. 

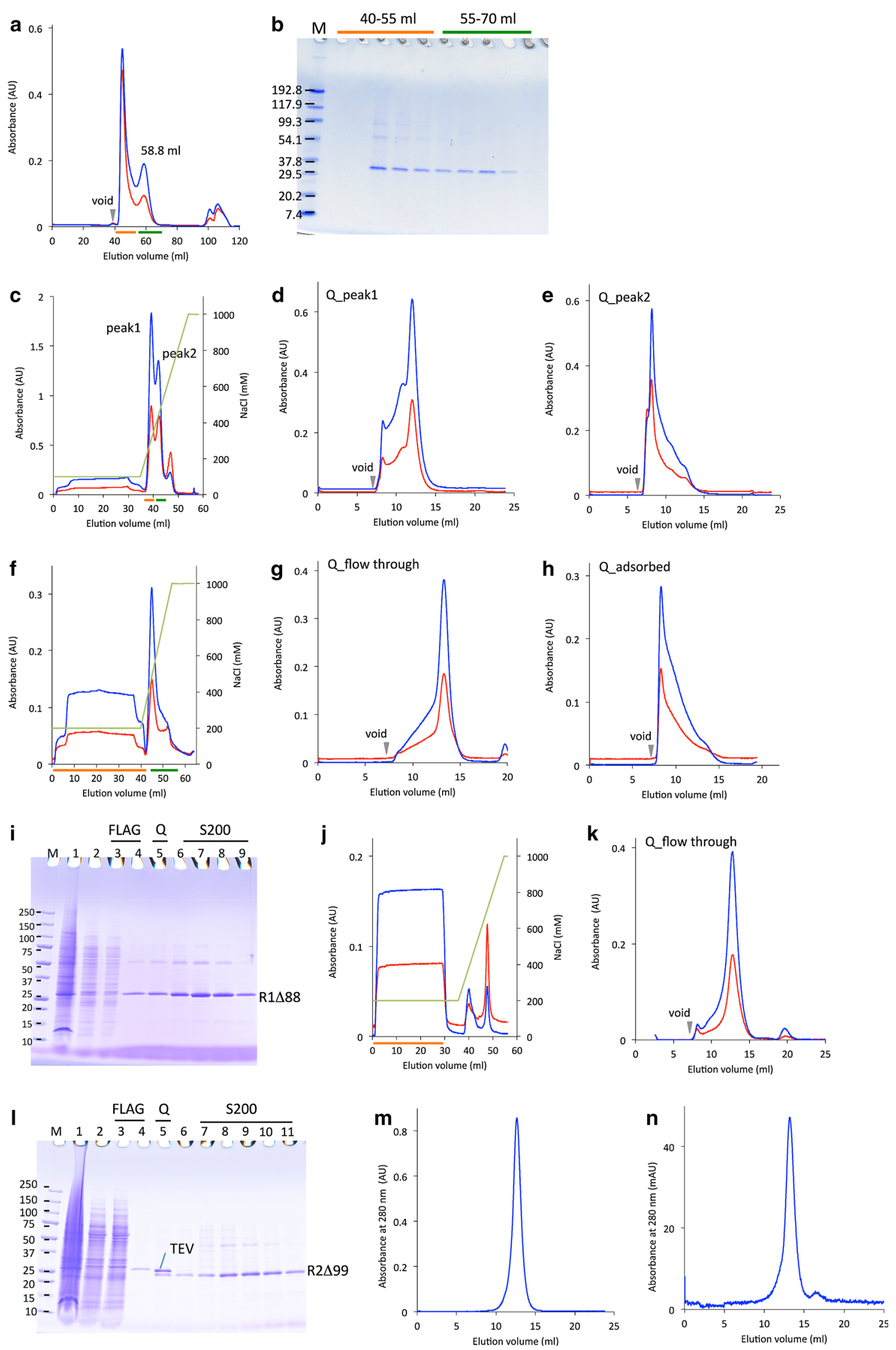

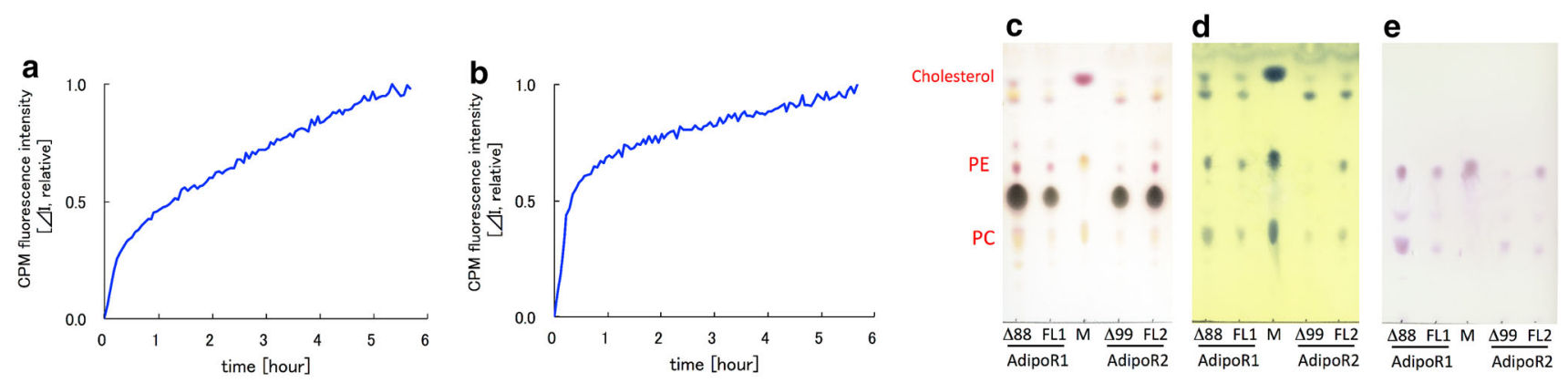

Fig. 4 Characterization of the purified AdipoR $1 \Delta 88$ and AdipoR2 $\Delta 99$ proteins. a, b CPM assay of AdipoR1 $\Delta 88$ (a) and AdipoR2 $\Delta 99$ (b). c-e TLC analysis of AdipoR1 $\Delta 88(\Delta 88)$, the full-length AdipoR1 (FL1), AdipoR2 $\Delta 99$ ( $\Delta 99)$, and the full-length

Large-scale preparations of $\mathrm{N}$-terminally truncated AdipoR1 and AdipoR2

The FLAG-tagged AdipoR1 $\Delta 88$ and AdipoR2 $\Delta 99$ were overexpressed in baculovirus-infected High Five insect cells. In general, membrane proteins are purified by minimal steps of chromatography, such as one-step affinity chromatography or two-step (affinity and sizeexclusion) chromatography, to avoid deterioration caused by delipidation due to excessive washing with detergents. Therefore, the FLAG-tagged AdipoR1 $\Delta 88$ was partially purified by stepwise FLAG affinity chromatography, and then fractionated by gel filtration chromatography, in which the AdipoR1 $\Delta 88$ eluted from the void volume (40 ml) to $70 \mathrm{ml}$, and formed two peaks (Fig. 3a, b). In this large-scale preparation, the affinity-purified AdipoR1 $\Delta 88$ behaved differently in the gel filtration (Fig. 3a, b), as compared to the small-scale SEC analysis (Fig. 2c, d). The low molecular mass fraction eluting at $58.8 \mathrm{ml}$ (Fig. 3a) was considered to correspond to the monodisperse fraction of AdipoR1 $\Delta 88$ eluting at $13 \mathrm{ml}$ in the small-scale SEC analysis. On the other hand, the high molecular mass, aggregated fraction was drastically larger in the large-scale preparation, as compared to the smallscale preparation (Figs. 2c, 3a). Therefore, the affinitypurified AdipoR1 $\Delta 88$ still aggregated during the sample concentration for gel filtration chromatography, as in the case of the full-length AdipoR1 (Fig. 1), although the properties of AdipoR1 were greatly improved by the $\mathrm{N}$-terminal deletion $(\Delta 88)$.

Accordingly, we explored the cause of the aggregation. As compared with the monodisperse fraction, the aggregated fraction exhibited a stronger absorbance at $254 \mathrm{~nm}$ relative to that at $280 \mathrm{~nm}$ (Fig. 3a). Therefore, we hypothesized that nucleic acids contained in the FLAGaffinity-purified AdipoR1 $\Delta 88$ preparation promoted protein aggregation. To quickly remove the putative nucleic acid contamination, we included an anion-exchange
AdipoR2 (FL2). The lipids were visualized with acetic acid/sulfuric acid $[1: 1(\mathrm{v} / \mathrm{v})](\mathbf{c})$, the phosphomolybdic reagent (d), and the ninhydrin reagent (e). Lane $M$, polar lipid mixture (Matreya)

column chromatography step immediately after the FLAG affinity chromatography. The FLAG-tagged AdipoR1 $\Delta 88$, in buffer A containing 100 or $200 \mathrm{mM} \mathrm{NaCl}$, was applied to a 1-ml HiTrap Q column. The FLAG-tagged AdipoR1 $\Delta 88$, in buffer A containing $100 \mathrm{mM} \mathrm{NaCl}$, was adsorbed on the column and eluted at low salt concentrations (150-250 mM NaCl) (Fig. 3c-e), whereas that in buffer A containing $200 \mathrm{mM} \mathrm{NaCl}$ was eluted in the flowthrough fraction (Fig. 3f-i). On the other hand, the aggregated AdipoR1 $\Delta 88$ was adsorbed on the column with either $100 \mathrm{mM}$ or $200 \mathrm{mM} \mathrm{NaCl}$, and was eluted at high salt concentrations (250-400 mM NaCl) (Fig. 3c, e, f, h). Thus, we could quickly separate the "intact" FLAG-tagged AdipoR1 $\Delta 88$ from the aggregated AdipoR1 $\Delta 88$, in buffer A containing $200 \mathrm{mM} \mathrm{NaCl}$, by anion-exchange chromatography (Fig. 3f, g). Once it was purified in this manner, the "intact" FLAG-tagged AdipoR1 $\Delta 88$ did not undergo the fast aggregation, and was eluted as a symmetrical peak in gel filtration chromatography. In other words, the "rotten apple" (the nucleic acid-aggregated AdipoR1) can be removed quickly by the anion-exchange chromatography, before it "spoils the barrel". As the cause of the aggregation had been found, we tried another method to reduce it: the sonication of the membrane preparation was also useful for breaking up nucleic acids, and the aggregation of the receptors was significantly reduced during the purification step.

In the same manner, the affinity-purified FLAG-tagged AdipoR2 $\Delta 99$, in buffer A containing $200 \mathrm{mM} \mathrm{NaCl}$, was eluted in the flow-through fraction in the HiTrap Q column chromatography (Fig. 3j-1). The FLAG tag of AdipoR2 $\Delta 99$ was removed after the HiTrap Q column chromatography. Thus, the FLAG-tagged AdipoR $1 \Delta 88$ and the untagged AdipoR $2 \Delta 99$ were purified to near homogeneity (Fig. $3 \mathrm{~m}, \mathrm{n}$ ). Removing the nucleic acids during the membrane preparation and the early stages of purification was essential to obtain larger amounts of the highly homogeneous AdipoR1 and AdipoR2 proteins. 


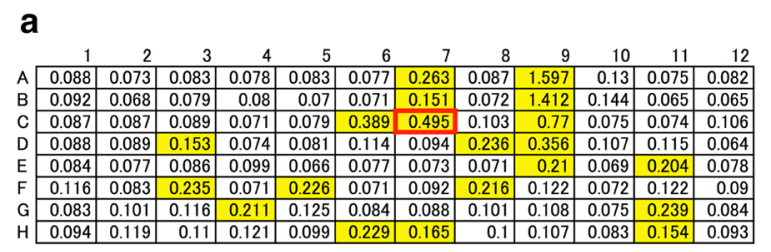

C

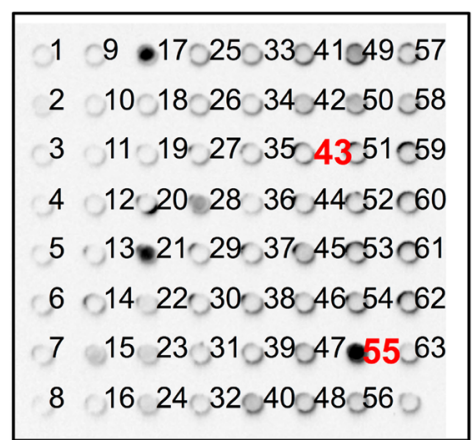

Fig. 5 Screening of anti-AdipoR1 antibodies. a Representative ELISA plate results. Yellow areas represent ELISA positive clones. Well C7, enclosed in a red box, indicates clone \#43. b FSEC analyses of IgG\#43 (top) and IgG\#55 (bottom). Peaks $p 1, p 2$, and $p 3$ represent the peak of the ternary complex (AdipoR $1 \Delta 88$, the antibody from hybridoma cells, and the fluorescein-Fab fragment), the antibody

Characterization of the purified AdipoR $1 \Delta 88$ and AdipoR2 $\Delta 99$ proteins

First, the stabilities of the purified AdipoR1 $\Delta 88$ and AdipoR $2 \Delta 99$ proteins were analyzed by the CPM assay method $[14,15]$ (Fig. 4a, b). When the $t_{1 / 2}$ value of thermal denaturation at $40{ }^{\circ} \mathrm{C}$ is 17 min or longer, the membrane protein is considered to be sufficiently stable [31]. The corresponding $t_{1 / 2}$ values of our AdipoR $1 \Delta 88$ and AdipoR $2 \Delta 99$ proteins are 74 and $20 \mathrm{~min}$, respectively. The CPM profile of AdipoR2 $\Delta 99$ revealed two phases, fast and slow, probably corresponding to the exposed and transmembrane cysteine residues, respectively, among which the latter reflect the stability of the transmembrane structure. In fact, AdipoR $2 \Delta 99$ has more exposed cysteine residues than AdipoR1 $\Delta 88$. Therefore, the $t_{1 / 2}$ value of 20 min for AdipoR2 $\Delta 99$ may be an underestimate. Consequently, we concluded that both of the present preparations of AdipoR $1 \Delta 88$ and AdipoR $2 \Delta 99$ are sufficiently stable. Second, the lipids that co-purified with the AdipoR1 $\Delta 88$ and AdipoR2 $\Delta 99$ in these preparations were analyzed by TLC [32] (Fig. 4c-e). Several lipid species copurified with AdipoR1 $\Delta 88$ and AdipoR2 $\Delta 99$, as well as the full-length proteins, indicating that the "bound lipids", which are important for the native folding of the membrane proteins, are probably retained in these preparations. Third, the purified AdipoR1 $\Delta 88$ protein was reconstituted into
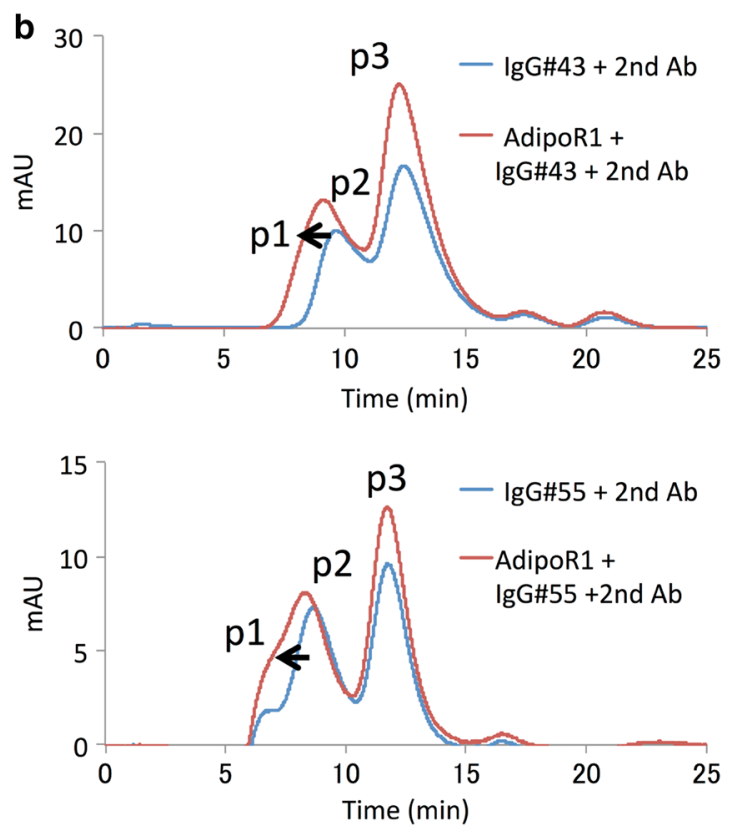

complex (the antibody from hybridoma cells and the fluorescein-Fab fragment), and the free fluorescein-Fab fragment, respectively. c SDS-denatured dot blot screening of anti-AdipoR1 antibodies. IgG\#17, IgG\#21, and IgG\#55 stained denatured AdipoR1. IgG\#43 and $\mathrm{IgG} \# 55$ are numbered in red

liposomes by the reported method [33]. The reconstituted proteoliposomes exhibited the binding activity for osmotin $\left(K_{\mathrm{D}}=0.7 \mu \mathrm{M} ; R_{\max }=49.2 \mathrm{RU}\right)$ in the SPR analysis. Together, these results confirmed that we have successfully prepared structurally and functionally intact samples of AdipoR1 and AdipoR2 that are suitable for crystallization.

Thus, crystallization trials of AdipoR $1 \Delta 88$ and AdipoR2 $\Delta 99$ were performed with commercially available kits, such as MemStart, MemSys, and MemGold (Molecular Dimensions), by the vapor diffusion method. First, AdipoR2 $\Delta 99$ crystals were obtained in one of the MemGold kit conditions. Despite extensive attempts to optimize the crystallization conditions to improve the crystal quality, no diffraction was obtained from these crystals. Furthermore, crystallization trials by the lipidic mesophase method were performed for the AdipoR $1 \Delta 88$ and AdipoR2 $\Delta 99$ preparations. However, crystals were obtained only in a limited number of conditions, and their diffractions were all poor (data not shown). Consequently, these results indicated that improvement of the crystal packing was necessary.

Antibody generation

Antibody fragments are useful tools to improve the resolution in membrane protein crystallography [34]. In fact, GPCRs, such as the $\beta_{2}$ adrenergic receptor and the $A_{2 A}$ 

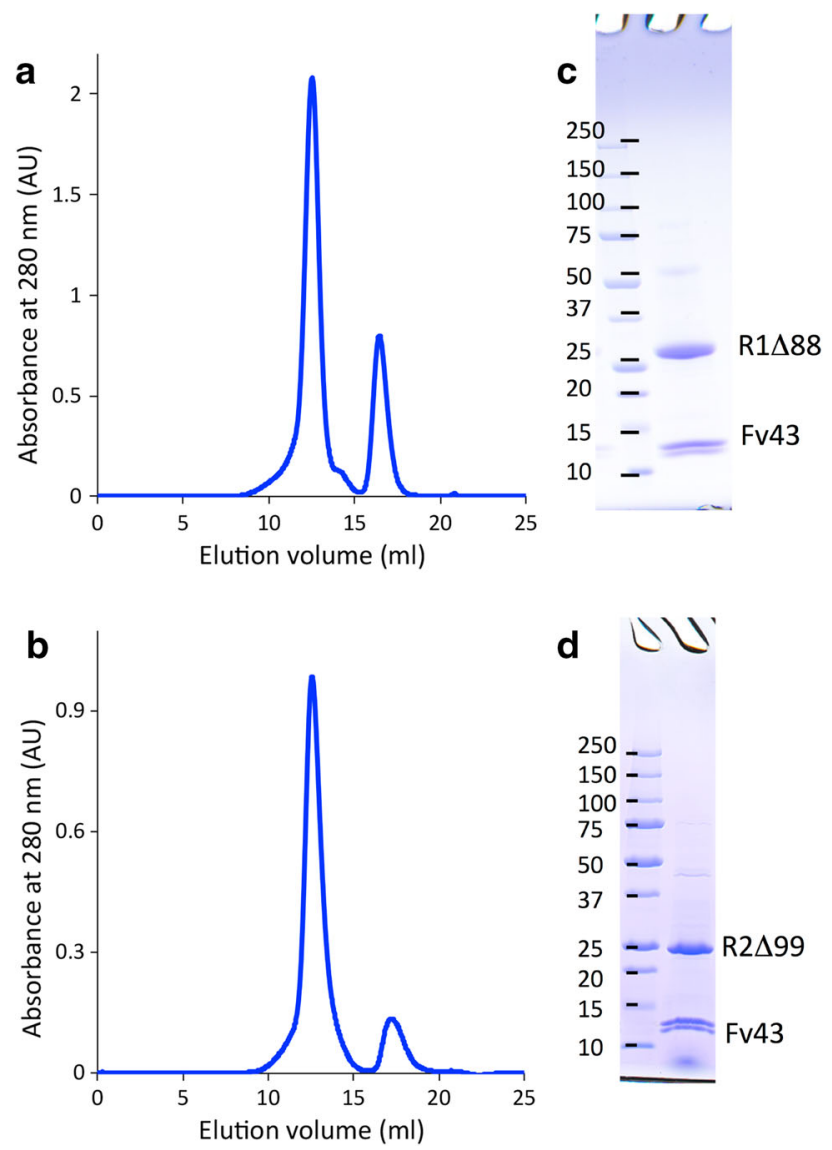

Fig. 6 Isolation of the AdipoR1 $\Delta 88 \cdot F v 43$ and AdipoR2 $\Delta 99 \cdot \mathrm{Fv} 43$ complexes. a, b Gel filtration chromatograms of the AdipoR1 $\Delta 88 \cdot \mathrm{Fv} 43$ (a) and AdipoR2 $\Delta 99 \cdot \mathrm{Fv} 43$ (b) complexes. c, d SDS-PAGE analysis of the crystallization samples of the AdipoR1 $\Delta 88 \cdot \mathrm{Fv} 43$ (c) and AdipoR2 $\Delta 99 \cdot \mathrm{Fv} 43$ (d) complexes

adenosine receptor, were co-crystallized with antibody fragments [35, 36]. Therefore, we planned to produce a high affinity and conformational epitope-recognizing antiAdipoR1 antibody, to improve the crystal packing of AdipoR1. The purified untagged AdipoR1 $\Delta 88$ was reconstituted into liposomes, and the resultant proteoliposomes were used as the immunogen. Mouse anti-AdipoR1 antibodies were produced by a conventional hybridoma system. Proteoliposomes containing the purified AdipoR $1 \Delta 88$ and biotinyl-PE were used for screening the antibodies by ELISA (liposome-ELISA). In the first round of liposomeELISA from 960 wells of hybridoma cultures, 72 positive wells were selected (Fig. 5a). Subsequently, 11 positive clones were selected in the second round of liposomeELISA and FSEC (Fig. 5b). Finally, 2 stable hybridoma cell lines (clone \#43 and clone \#55) were established. The

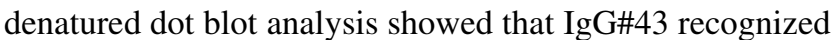
the native conformation of AdipoR1, whereas IgG\#55 recognized the linear epitope (Fig. 5c). In addition, ELISA

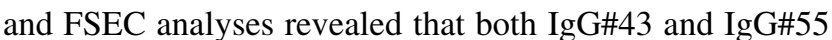
cross-reacted with AdipoR2 $\Delta 99$ (data not shown). The
cDNAs encoding the $V_{H}$ and $V_{L}$ regions of $\operatorname{IgG} \# 43$ were cloned from hybridoma cells, according to the standard method [18]. The very N-terminal amino acid residues of the $\mathrm{V}_{\mathrm{H}}$ and $\mathrm{V}_{\mathrm{L}}$ fragments were determined by Edman degradation, and the 15 residue sequences of the $\mathrm{N}$-termini of the $V_{H}$ and $V_{L}$ regions from clone $\# 43$ were determined as EVLLQQSGPELVKPG and DIQMTQSPASLSASV, respectively. The base sequences of the cloned cDNAs were corrected accordingly. The variable region of IgG\#43 (Fv43) was synthesized by the $E$. coli cell-free protein synthesis method, and purified to homogeneity by column chromatography. The yield of the purified Fv43 was $0.3 \mathrm{mg}$ per $1 \mathrm{ml}$ cell-free synthesis reaction.

\section{Data collection and processing}

The cell-free produced Fv43 was mixed with the purified AdipoR1 $\Delta 88$ and AdipoR2 $\Delta 99$, and the AdipoR1 $\Delta 88 \cdot F v 43$ and AdipoR2 $\Delta 99 \cdot \mathrm{Fv} 43$ complexes were isolated by gel filtration chromatography (Fig. 6). The AdipoR1 $\Delta 88 \cdot F v 43$ and AdipoR2 $\Delta 99 \cdot \mathrm{Fv} 43$ complexes were crystallized by the lipidic mesophase method. The AdipoR $1 \Delta 88 \cdot$ Fv 43 crystals with 10-15 $\mu \mathrm{m}$ lengths were obtained in $100 \mathrm{mM}$ bicine buffer ( $\mathrm{pH}$ 8.0) containing 50-150 mM MgSO 4 and 29-33\% (v/v) PEG400 (Fig. 7a, b). The AdipoR2 $\Delta 99 \cdot$ Fv43 crystals with $30-40 \mu \mathrm{m}$ lengths were obtained in $100 \mathrm{mM}$ Na-citrate buffer ( $\mathrm{pH}$ 6.0) containing $375-425 \mathrm{mM}$ K-citrate and 28-30 \% (v/v) PEG400 (Fig. 7c, d). The crystals reached their full sizes within one week.

We successfully collected all of the data sets by the helical scan method, with a microbeam of $1 \mu \mathrm{m} \times 10 \mu \mathrm{m}$ (horizontal $\times$ vertical) at beamline BL32XU at SPring-8 [24-26]. The AdipoR1 $\Delta 88 \cdot F v 43$ and AdipoR2 $\Delta 99 \cdot F v 43$ crystals diffracted up to 2.8 and $2.2 \AA$ resolutions, respectively (Fig. 8). Data collection from the AdipoR1 crystal was limited to 10-30 images per crystal, due to radiation damage in the microcrystals, and therefore the data from six crystals were merged to complete the data set. The diffraction data of the AdipoR2 crystal were collected from a single crystal. The data collection statistics are shown in Table 1 . The AdipoR1 $\Delta 88 \cdot \mathrm{Fv} 43$ and AdipoR2 $\Delta 99 \cdot \mathrm{Fv} 43$ crystals belonged to the space groups $C 222_{1}$, with unit cell parameters $a=92.7, b=194.4$, $c=74.4 \AA$, and $P 2{ }_{1} 2{ }_{1} 2$, with unit cell parameters $a=74.6$, $b=108.6, c=101.0 \AA$, respectively. Under the assumption that the asymmetric unit contained one AdipoR1 $\Delta 88 \cdot$ Fv43 complex or one AdipoR2 $\Delta 99 \cdot \mathrm{Fv} 43$ complex, the Matthews coefficients of the AdipoR1 $\Delta 88 \cdot$ Fv43 and AdipoR2 $\Delta 99 \cdot F v 43$ complexes were calculated to be $2.8 \AA^{3} \mathrm{Da}^{-1}$ with a solvent content of $56.1 \%$ and $3.6 \AA^{3} \mathrm{Da}^{-1}$ with a solvent content of $65.4 \%$, respectively. An initial phase for the AdipoR2 $\Delta 99$. Fv43 complex was obtained by molecular replacement using the $\mathrm{FV}$ fragment (the $\mathrm{V}_{\mathrm{H}}$ and $\mathrm{V}_{\mathrm{L}}$ fragments from 


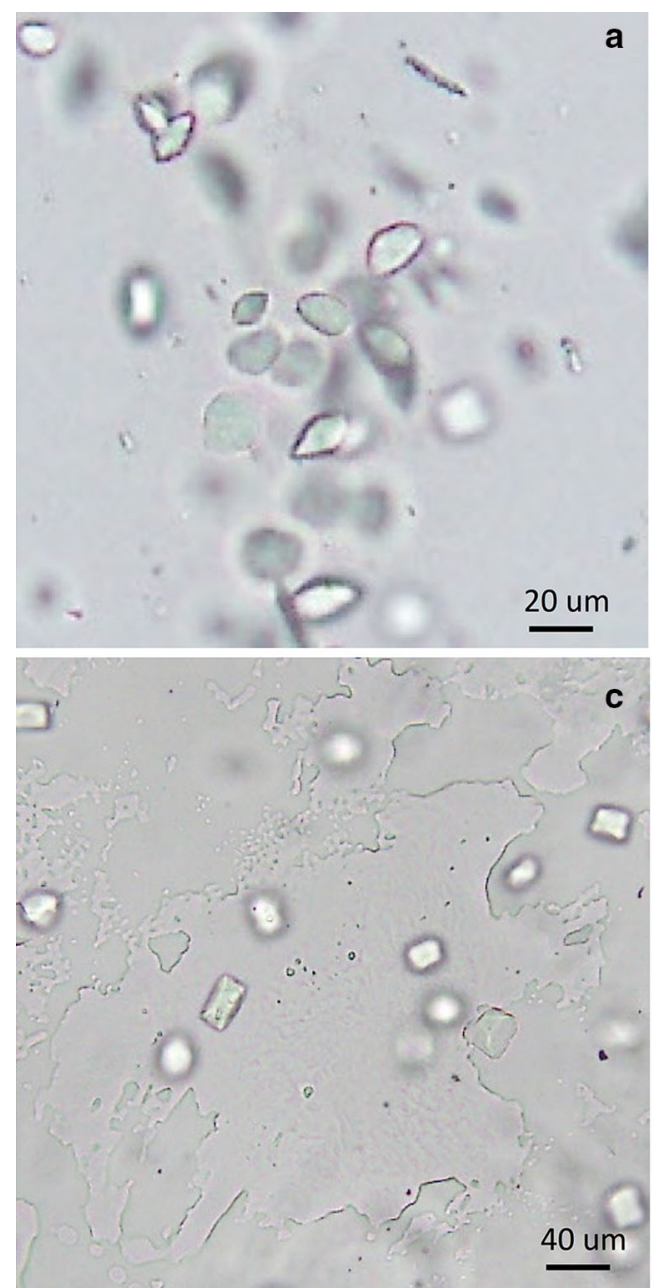

Fig. 7 Crystals of the FLAG-tagged AdipoR1 $\Delta 88 \cdot$ Fv 43 and AdipoR2 $\Delta 99$.Fv43 complexes. a, b Crystals of the FLAG-tagged AdipoR1 $\Delta 88 \cdot$ Fv 43 complex. c, d Crystals of the AdipoR2 $\Delta 99 \cdot \mathrm{Fv} 43$
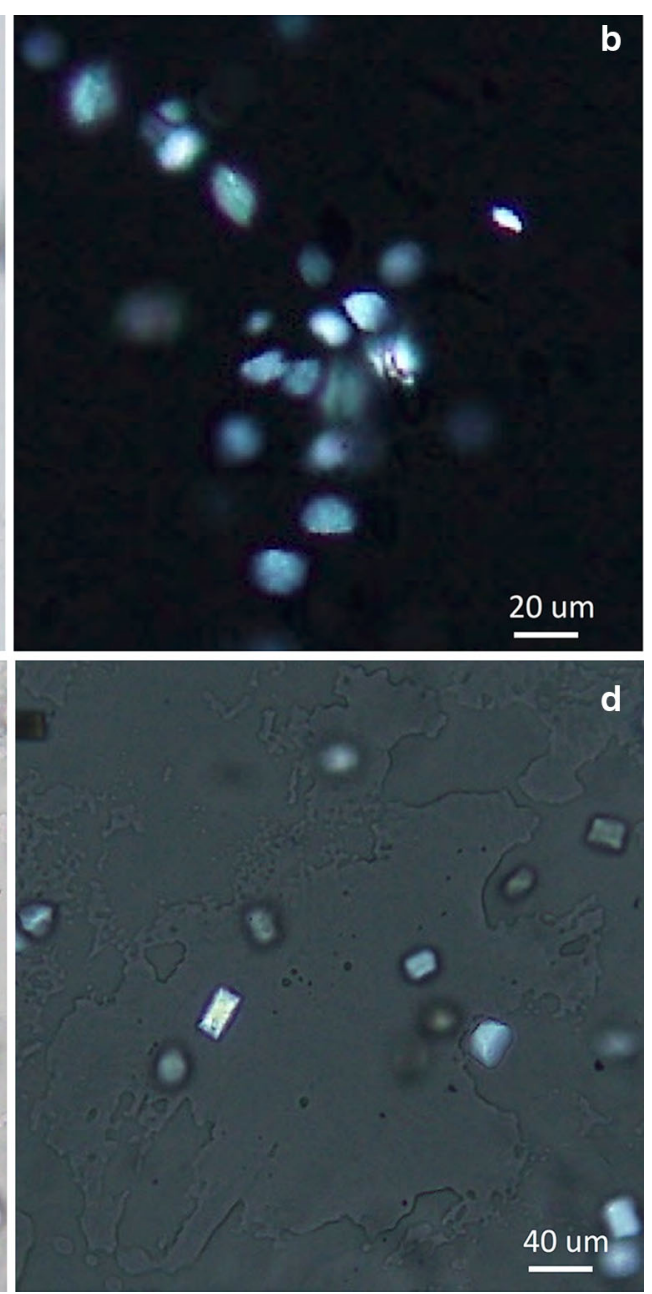

complex. Crystals are shown in bright field $(\mathbf{a}, \mathbf{c})$ and under crossed polarizers $(\mathbf{b}, \mathbf{d})$
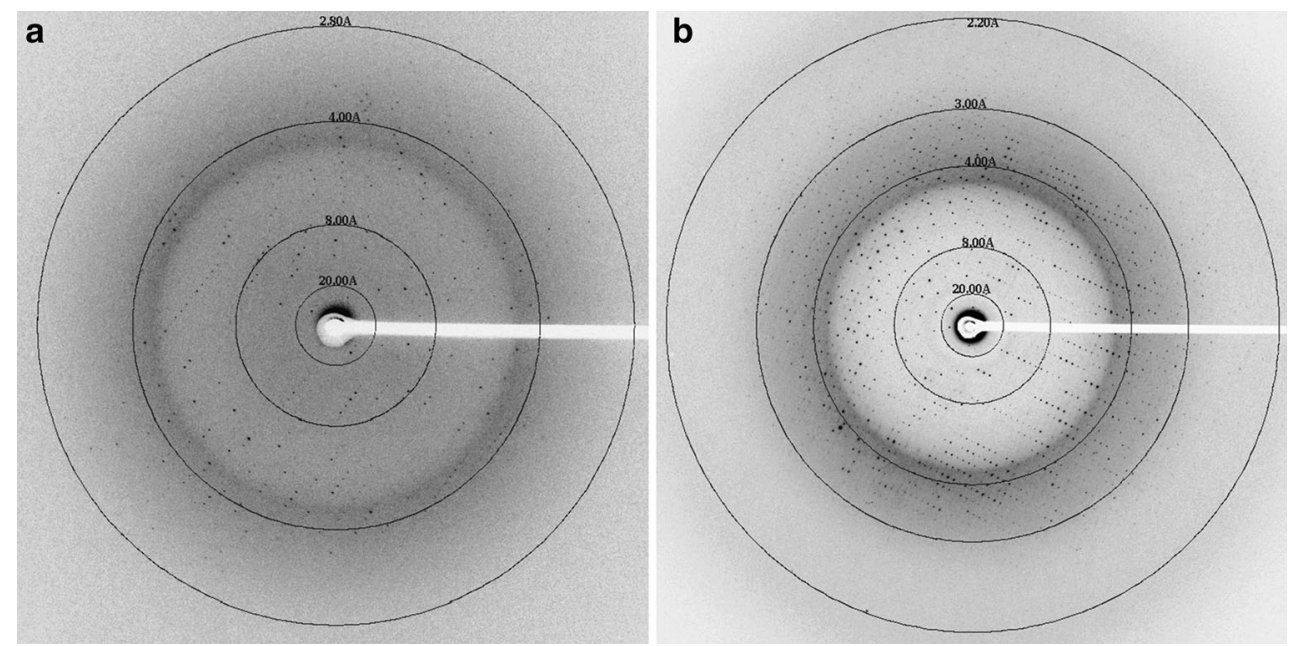

Fig. 8 X-ray diffraction images of the AdipoR1 $\Delta 88 \cdot F v 43$ complex (a) and the AdipoR2 $\Delta 99 \cdot$ Fv43 complex (b) 
Table 1 Data collection statistics

\begin{tabular}{|c|c|c|}
\hline Structure & $\begin{array}{l}\text { AdipoR1 } 188 \cdot \mathrm{Fv} 43 \\
\text { complex }\end{array}$ & $\begin{array}{l}\text { AdipoR } 2 \Delta 99 \cdot \mathrm{Fv} 43 \\
\text { complex }\end{array}$ \\
\hline No. of crystals & 6 & 1 \\
\hline X-ray source & BL32XU, SPring-8 & BL32XU, SPring- 8 \\
\hline Wavelength $(\AA)$ & 1 & 1 \\
\hline Space group & $C 222_{1}$ & $P 2{ }_{1} 2{ }_{1}$ \\
\hline \multicolumn{3}{|l|}{ Cell dimensions } \\
\hline$a, b, c(\AA)$ & $92.7,194.4,74.4$ & $74.6,108.6,101.0$ \\
\hline$\alpha, \beta, \gamma\left(^{\circ}\right)$ & $90.0,90.0,90.0$ & $90.0,90.0,90.0$ \\
\hline $\begin{array}{l}\text { No. of reflections } \\
\text { measured }\end{array}$ & 135111 & 145165 \\
\hline $\begin{array}{l}\text { No. of unique } \\
\text { reflections }\end{array}$ & 16509 & 32174 \\
\hline Resolution (£) & $\begin{array}{l}20.00-2.80 \\
\quad(2.90-2.80)\end{array}$ & $\begin{array}{l}19.52-2.40 \\
\quad(2.49-2.40)\end{array}$ \\
\hline$R_{\text {merge }}$ & $0.176(>1)$ & $0.115(1.297)$ \\
\hline Mean $I / \sigma(I)$ & $8.5(1.3)$ & $8.6(1.2)$ \\
\hline Completeness (\%) & $97.2(99.1)$ & $98.3(99.4)$ \\
\hline Redundancy & $8.2(8.0)$ & $4.5(4.5)$ \\
\hline $\mathrm{V}_{\mathrm{M}}\left(\AA^{3} \mathrm{Da}^{-1}\right)$ & 2.8 & 3.6 \\
\hline Solvent content $(\%)$ & 56.1 & 65.4 \\
\hline
\end{tabular}

Values in parentheses are for the outer shell

PDB IDs 1E6J and 1FDL, respectively) in Phaser [37] as search models. The refinement is in progress.

Acknowledgments This work was supported by grants from the Targeted Proteins Research Program (S.Y., T.K., S.I., and M.Y.) and the Platform for Drug Discovery, Informatics, and Structural Life Science (S.Y. and M.Y.) from the Ministry of Education, Culture, Sports, Science and Technology of Japan, and by the research acceleration program of the Japan Science and Technology Agency (S.I.). We thank M. Toyama, M. Inoue, M. Goto, M. Aoki, and K. Ishii for expression plasmid preparation, M. Nishimoto, Y. Tomabechi, and Y. Terazawa for technical assistance with protein expression and purification, and R. Akasaka for protein analysis. The synchrotron radiation experiments were performed on BL32XU at SPring-8 (Proposal Nos. 2012A1332, 2012B1453, 2013B1034, 2014A1008, and 2014A1186) with the approval of RIKEN. We are also grateful to the staffs of I24 (Diamond Light Source) and X06SA (Swiss Light Source) for assistance with data collection.

Open Access This article is distributed under the terms of the Creative Commons Attribution License which permits any use, distribution, and reproduction in any medium, provided the original author(s) and the source are credited.

\section{References}

1. Scherer PE, Williams S, Fogliano M, Baldini G, Lodish HF (1995) A novel serum protein similar to C1q, produced exclusively in adipocytes. J Biol Chem 270(45):26746-26749

2. Hu E, Liang P, Spiegelman BM (1996) AdipoQ is a novel adipose-specific gene dysregulated in obesity. J Biol Chem 271 (18):10697-10703
3. Maeda K, Okubo K, Shimomura I, Funahashi T, Matsuzawa Y, Matsubara K (1996) cDNA cloning and expression of a novel adipose specific collagen-like factor, apM1 (AdiPose Most abundant Gene transcript 1). Biochem Biophys Res Commun 221(2):286-289

4. Nakano Y, Tobe T, Choi-Miura NH, Mazda T, Tomita M (1996) Isolation and characterization of GBP28, a novel gelatin-binding protein purified from human plasma. J Biochem 120(4):803-812

5. Hotta K, Funahashi T, Arita Y, Takahashi M, Matsuda M, Okamoto Y, Iwahashi H, Kuriyama H, Ouchi N, Maeda K, Nishida M, Kihara S, Sakai N, Nakajima T, Hasegawa K, Muraguchi M, Ohmoto Y, Nakamura T, Yamashita S, Hanafusa T, Matsuzawa Y (2000) Plasma concentrations of a novel, adiposespecific protein, adiponectin, in type 2 diabetic patients. Arterioscler Thromb Vasc Biol 20(6):1595-1599

6. Yamauchi T, Kamon J, Ito Y, Tsuchida A, Yokomizo T, Kita S, Sugiyama T, Miyagishi M, Hara K, Tsunoda M, Murakami K, Ohteki T, Uchida S, Takekawa S, Waki H, Tsuno NH, Shibata Y, Terauchi Y, Froguel P, Tobe K, Koyasu S, Taira K, Kitamura T, Shimizu T, Nagai R, Kadowaki T (2003) Cloning of adiponectin receptors that mediate antidiabetic metabolic effects. Nature 423(6941):762-769

7. Tomas E, Tsao TS, Saha AK, Murrey HE, Zhang CC, Itani SI, Lodish HF, Ruderman NB (2002) Enhanced muscle fat oxidation and glucose transport by ACRP30 globular domain: acetyl-CoA carboxylase inhibition and AMP-activated protein kinase activation. Proc Natl Acad Sci USA 99(25):16309-16313

8. Yamauchi T, Kamon J, Minokoshi Y, Ito Y, Waki H, Uchida S, Yamashita S, Noda M, Kita S, Ueki K, Eto K, Akanuma Y, Froguel P, Foufelle F, Ferre P, Carling D, Kimura S, Nagai R, Kahn BB, Kadowaki T (2002) Adiponectin stimulates glucose utilization and fatty-acid oxidation by activating AMP-activated protein kinase. Nat Med 8(11):1288-1295

9. Kahn BB, Alquier T, Carling D, Hardie DG (2005) AMP-activated protein kinase: ancient energy gauge provides clues to modern understanding of metabolism. Cell Metab 1(1):15-25

10. Iwabu M, Yamauchi T, Okada-Iwabu M, Sato K, Nakagawa T, Funata M, Yamaguchi M, Namiki S, Nakayama R, Tabata M, Ogata H, Kubota N, Takamoto I, Hayashi YK, Yamauchi N, Waki H, Fukayama M, Nishino I, Tokuyama K, Ueki K, Oike Y, Ishii S, Hirose K, Shimizu T, Touhara K, Kadowaki T (2010) Adiponectin and AdipoR1 regulate PGC- $1 \alpha$ and mitochondria by $\mathrm{Ca}^{2+}$ and AMPK/SIRT1. Nature 464(7293):1313-1319

11. Kersten S, Desvergne B, Wahli W (2000) Roles of PPARs in health and disease. Nature 405(6785):421-424

12. Yamauchi T, Kamon J, Waki H, Imai Y, Shimozawa N, Hioki K, Uchida S, Ito Y, Takakuwa K, Matsui J, Takata M, Eto K, Terauchi Y, Komeda K, Tsunoda M, Murakami K, Ohnishi Y, Naitoh T, Yamamura K, Ueyama Y, Froguel P, Kimura S, Nagai R, Kadowaki T (2003) Globular adiponectin protected ob/ob mice from diabetes and ApoE-deficient mice from atherosclerosis. J Biol Chem 278(4):2461-2468

13. Wess J (1997) G-protein-coupled receptors: molecular mechanisms involved in receptor activation and selectivity of G-protein recognition. FASEB J 11(5):346-354

14. Alexandrov AI, Mileni M, Chien EY, Hanson MA, Stevens RC (2008) Microscale fluorescent thermal stability assay for membrane proteins. Structure 16(3):351-359

15. Hanson MA, Cherezov V, Griffith MT, Roth CB, Jaakola VP, Chien EY, Velasquez J, Kuhn P, Stevens RC (2008) A specific cholesterol binding site is established by the $2.8 \AA$ structure of the human $\beta_{2}$-adrenergic receptor. Structure 16(6):897-905

16. Kohler G, Milstein C (1975) Continuous cultures of fused cells secreting antibody of predefined specificity. Nature 256(5517): 495-497 
17. Hino T, Iwata S, Murata T (2013) Generation of functional antibodies for mammalian membrane protein crystallography. Curr Opin Struct Biol 23(4):563-568

18. Toleikis L, Broders O, Dubel S (2004) Cloning single-chain antibody fragments (scFv) from hybridoma cells. Methods Mol Med 94:447-458

19. Yabuki T, Motoda Y, Hanada K, Nunokawa E, Saito M, Seki E, Inoue M, Kigawa T, Yokoyama S (2007) A robust two-step PCR method of template DNA production for high-throughput cellfree protein synthesis. J Struct Funct Genomics 8(4):173-191

20. Kigawa T, Yabuki T, Matsuda N, Matsuda T, Nakajima R, Tanaka A, Yokoyama S (2004) Preparation of Escherichia coli cell extract for highly productive cell-free protein expression. J Struct Funct Genomics 5(1-2):63-68

21. Matsuda T, Watanabe S, Kigawa T (2013) Cell-free synthesis system suitable for disulfide-containing proteins. Biochem Biophys Res Commun 431(2):296-301

22. Hato M, Yamashita J, Shiono M (2009) Aqueous phase behavior of lipids with isoprenoid type hydrophobic chains. J Phys Chem B 113(30):10196-10209

23. Hato M, Hosaka T, Tanabe H, Kitsunai T, Yokoyama S (2014) A new manual dispensing system for in meso membrane protein crystallization with using a stepping motor-based dispenser. J Struct Funct Genomics 15(3):165-171

24. Ueno G, Kanda H, Kumasaka T, Yamamoto M (2005) Beamline Scheduling Software: administration software for automatic operation of the RIKEN structural genomics beamlines at SPring8. J Synchrotron Radiat 12(Pt 3):380-384

25. Murakami I, Fujii T, Kameyama K, Iwata T, Saito M, Kubushiro K, Aoki D (2012) Tumor volume and lymphovascular space invasion as a prognostic factor in early invasive adenocarcinoma of the cervix. J Gynecol Oncol 23(3):153-158

26. Hirata K, Kawano Y, Ueno G, Hashimoto K, Murakami H, Hasegawa K, Hikima T, Kumasaka T, Yamamoto M (2013) Achievement of protein micro-crystallography at SPring-8 beamline BL32XU. J Phys Conf Ser 425:012002

27. Otwinowski Z, Minor W (1997) Processing of X-ray diffraction data collected in oscillation mode. Methods Enzymol 276:307-327
28. Kabsch W (2010) Xds. Acta Crystallogr D Biol Crystallogr 66(Pt 2):125-132

29. Buchan DW, Minneci F, Nugent TC, Bryson K, Jones DT (2013) Scalable web services for the PSIPRED protein analysis workbench. Nucleic Acids Res 41(Web Server issue):W349-W357

30. Tusnady GE, Simon I (2001) The HMMTOP transmembrane topology prediction server. Bioinformatics 17(9):849-850

31. Sonoda Y, Newstead S, Hu NJ, Alguel Y, Nji E, Beis K, Yashiro S, Lee C, Leung J, Cameron AD, Byrne B, Iwata S, Drew D (2011) Benchmarking membrane protein detergent stability for improving throughput of high-resolution X-ray structures. Structure 19(1):17-25

32. Han X, Cheng H (2005) Characterization and direct quantitation of cerebroside molecular species from lipid extracts by shotgun lipidomics. J Lipid Res 46(1):163-175

33. Rigaud JL, Levy D (2003) Reconstitution of membrane proteins into liposomes. Methods Enzymol 372:65-86

34. Iwata S, Ostermeier C, Ludwig B, Michel H (1995) Structure at $2.8 \AA$ resolution of cytochrome $c$ oxidase from Paracoccus denitrificans. Nature 376(6542):660-669

35. Rasmussen SG, DeVree BT, Zou Y, Kruse AC, Chung KY, Kobilka TS, Thian FS, Chae PS, Pardon E, Calinski D, Mathiesen JM, Shah ST, Lyons JA, Caffrey M, Gellman SH, Steyaert J, Skiniotis G, Weis WI, Sunahara RK, Kobilka BK (2011) Crystal structure of the $\beta_{2}$ adrenergic receptor-Gs protein complex. Nature 477(7366):549-555

36. Hino T, Arakawa T, Iwanari H, Yurugi-Kobayashi T, Ikeda-Suno C, Nakada-Nakura Y, Kusano-Arai O, Weyand S, Shimamura T, Nomura N, Cameron AD, Kobayashi T, Hamakubo T, Iwata S, Murata T (2012) G-protein-coupled receptor inactivation by an allosteric inverse-agonist antibody. Nature 482(7384):237-240

37. McCoy AJ, Grosse-Kunstleve RW, Adams PD, Winn MD, Storoni LC, Read RJ (2007) Phaser crystallographic software. J Appl Crystallogr 40(Pt 4):658-674

38. Larkin MA, Blackshields G, Brown NP, Chenna R, McGettigan PA, McWilliam H, Valentin F, Wallace IM, Wilm A, Lopez R, Thompson JD, Gibson TJ, Higgins DG (2007) Clustal W and Clustal X version 2.0. Bioinformatics 23(21):2947-2948 